\title{
2 Verwendete Transkriptionskonventionen nach GAT 2
}

Die folgenden Transkriptionskonventionen wurden für die Aufbereitung der Gesprächsdaten in Anlehnung an Selting et al. (2009: 391-392) verwendet:

\section{Minimaltranskript}

Sequenzielle Struktur/Verlaufsstruktur

[ ] Überlappungen und Simultansprechen

$\underline{\text { Pausen }}$

(. ) Mikropause, geschätzt, bis ca. 0.2 Sek. Dauer

(-) kurze geschätzte Pause von ca. 0.2-0.5 Sek. Dauer

(-) mittlere geschätzte Pause v. ca. 0.5-0.8 Sek. Dauer

(---) längere geschätzte Pause von ca. 0.8-1.0 Sek. Dauer

(0.5) gemessene Pausen von ca. 0.5 bzw. 2.0 Sek. Dauer

(2.0) (Angabe mit einer Stelle hinter dem Punkt)

$\underline{\text { Sonstige segmentale Konventionen }}$

und_äh Verschleifungen innerhalb von Einheiten

äh oh ähm Verzögerungssignale, sog. „gefüllte Pausen“

Lachen und Weinen

$\begin{array}{ll}\text { haha hehe hihi } & \text { silbisches Lachen } \\ ((\text { lacht }))((\text { weint })) & \text { Beschreibung des Lachens } \\ <<\text { lachend }> & \text { Lachpartikeln in der Rede, mit Reichweite } \\ <<:-)>\text { soo }> & \text { "smile voice“ }\end{array}$


$\underline{\text { Rezeptionssignale }}$
hm ja nein nee
einsilbige Signale
hm_hm ja_ja
zweisilbige Signale
' $\mathrm{hm}$ ' hm,
mit Glottalverschlüssen, meistens verneinend

$\underline{\text { Sonstige Konventionen }}$
((hustet))
para- und außersprachliche Handlungen $u$.
Ereignisse
$<<$ hustend $>\quad>$
sprachbegleitende para- und außersprachliche
Handlungen $u$. Ereignisse mit Reichweite
$(x x x),(x x x \quad x x x)$
ein bzw. zwei unverständliche Silben
(solche/welche)
vermuteter Wortlaut bzw. mögliche Alternativen
((unverständlich, unverständliche Passage mit ggf. Angabe der Dauer ca. 3 Sek))
$((\ldots)) \quad$ Auslassung im Transkript

\section{Basistranskript}

Sequenzielle Struktur/Verlaufsstruktur

$=\quad$ schneller, unmittelbarer Anschluss neuer

Sprecherbeiträge oder Segmente (latching)

$\underline{\text { Sonstige segmentale Konventionen }}$

$\begin{array}{ll}: & \text { Dehnung, Längung, um ca. 0.2-0.5 Sek. } \\ :: & \text { Dehnung, Längung, um ca. 0.5-0.8 Sek. } \\ ::: & \text { Dehnung, Längung, um ca. 0.8-1.0 Sek. } \\ \text { : } & \text { Abbruch durch Glottalverschluss }\end{array}$

\section{$\underline{\text { Akzentuierung }}$}

akZENT

ak!ZENT!

akzEnt
Fokusakzent

extra starker Akzent

Nebenakzent (aus den Konventionen für

Feintranskripte übernommen) 


\section{Tonhöhenbewegung am Ende von Intonationsphrasen}

$?$

,

$-$

;

.

Sonstige Konventionen

$<$ <erstaunt $>\quad>\quad$ interpretierende Kommentare mit Reichweite hoch steigend

mittel steigend

gleichbleibend

mittel fallend

tief fallend 
